Final version:

Hingley, M.K., Lindgreen, A., Grant, D.B., and Kane, C. (2011), "Using fourth-party logistics management to improve horizontal collaboration among grocery retailers", Supply Chain Management: An International Journal, Vol. 16, No. 5, pp. 316-327. (ISSN 09574093)

For full article, please contact LindgreenA@cardiff.ac.uk

Supply Chain Management: An International Journal

\title{
Using Fourth-Party Logistics Management to Improve Horizontal Collaboration among Grocery Retailers
}

\author{
Martin Hingley, University of Lincoln, $\mathrm{UK}^{1}$ \\ Adam Lindgreen, University of Cardiff \& IESEG School of Management ${ }^{2}$ \\ David B. Grant, Heriot-Watt University \\ Charles Kane, Harper Adams University College
}

\footnotetext{
${ }^{1}$ The authors contributed equally.

${ }^{2}$ For all correspondence: Dr. Adam Lindgreen, Professor in marketing at the University of Cardiff \& Visiting professor at IESEG School of Management. Correspondence address: Professor Adam Lindgreen, Cardiff Business School, the University of Cardiff, Aberconway Building, Colum Drive, Cardiff CF10 3EU, the U.K. E-mail: LindgreenA@cardiff.ac.uk.
} 


\title{
Using Fourth-Party Logistics Management to Improve Horizontal Collaboration Among Grocery Retailers
}

\begin{abstract}
Purpose: There is a paucity of literature considering horizontal collaboration among grocery retailers, suppliers, and third-party logistics (3PL) providers. This article investigates benefits of and barriers to the use of fourth-party logistics (4PL) management as a catalyst for horizontal collaboration.

Design/methodology/approach: Three suppliers, three logistics service providers (LSPs), and one grocery retailer participated in semi-structured interviews for this exploratory qualitative study.

Findings: Large LSPs can establish 4PL management but the significant investment required to do so is a deterrent. Interviewees believed 4PL would negatively influence the grocery retailer-supplier dynamic but simultaneously would provide key potential benefits. Retaining supply chain control means more to grocery retailers than cost efficiencies realized through horizontal collaboration.
\end{abstract}

Research limitations: Fierce competition among major grocery chains means that most are unwilling to participate in studies of their systems, which restricts the research scope.

Practical implications: Some stakeholders want deeper integration into grocery supply networks, and the 4PL model could apply to diverse sectors and circumstances. This study shows that barriers to such integration are created by power plays among lead stakeholders in grocery retailing that inhibits horizontal collaboration regardless of cost or other benefits.

Originality/value: The study investigates an under-researched aspect of horizontal supply chain collaboration in the highly relevant retail grocery sector: a high volume, mass market industry that requires an enormous logistics infrastructure and highly embedded networks of relationships.

Keywords: Fourth-party logistics (4PL) management, retailers, suppliers, horizontal collaboration, grocery supply chains.

Paper type: Research paper. 


\section{Introduction}

The UK grocery retailing sector is an innovative leader in logistics and supply chain management practice and has pioneered many new techniques (Fernie and McKinnon, 2003; Hingley et al., 2006), including vertical collaboration between retailers and suppliers (Fernie and Hart, 2001; Lindgreen et al., 2009; Smith and Sparks, 2004). The sector also has promised horizontal and network collaboration (Fearne and Hughes, 1999; Hingley, 2005) leading to several initiatives that largely reflect efforts by industry trade associations (e.g., IGD, ECR UK), sometimes in association with academic researchers (e.g., Grant et al., 2008). However, little academic work empirically has investigated horizontal collaboration in this sector. This article considers several characteristics and issues related to horizontal collaboration implementation through an exploratory investigation of retailers, suppliers, and logistics service providers (LSPs) in the UK grocery retailing sector, focusing specifically on the role of fourth-party logistics (4PL) service providers. We develop four research questions pertaining to the benefits of and barriers to 4PL service providers acting as catalysts for horizontal collaboration.

We first discuss theoretical and practical developments related to horizontal collaboration in the grocery sector. Next we outline our case method to explore firms' attitudes to collaboration and the prospect for 4PL management. Then we investigate participants' ability and willingness to develop workable, profitable 4PL through exploratory depth interviews. Finally, we conclude with managerial implications, limitations of the study, and suggestions for further research.

\section{Literature Review}

\subsection{Relationships and Collaboration}

Collaboration is one form of an interfirm cooperative relationship (Kaufman et al., 2000), though the type of relationship undertaken by the parties varies according to several factors. Macneil (1980) proposed an exchange continuum between purely transactional and purely relational exchanges. Transactional exchanges are discrete dyadic exchanges between buyers and sellers with minimal personal relationships and no anticipation or obligation of future exchanges. Relational exchanges contain elements of cooperation, sharing, and planning on both sides in addition to exchanges with other relevant actors (Garbarino and Johnson, 1999).

Day (2000) argues that transactional exchanges are likely anonymous, automatic and driven by technology. This routinization of transactions is appropriate in commodity markets with certain demand and limited product variation. However, collaborative exchanges feature 
"very close information, social, and process linkages, and mutual commitments made in expectation of long-term benefits" (Day, 2000, p. 24) that appears similar to vertical integration. Such relationships build on trust and commitment obtained from shared values and information, mutual dependence, communication and relationship benefits (Lindgreen, 2003). However, environmental factors also affect relationships such as competition, sophisticated and fragmented customers, technological advances and product commoditization (Morgan and Hunt, 1994; Spekman et al., 1998).

In such settings horizontal and vertical integration offer two primary forms of supply chain collaboration (Barratt, 2004; Simatupang and Sridharan, 2002). Horizontal integration occurs when two or more unrelated or competing firms at the same level of the supply chain and producing similar products or different components of a single product form a cooperative association to share resources such as warehouse space or manufacturing capacity (Prakash and Deshmukh, 2010). Such horizontal integration or collaboration may overcome financial barriers to trade and benefit society by reducing the number of trucks on the road and thus congestion and carbon dioxide emissions (McKinnon and Edwards, 2010).

\subsection{Evolution of Logistics in UK Grocery Supply Chains: Seeds of Collaborative Distribution}

In the early 1980s, several grocery retailers shifted from direct store delivery to regionally controlled distribution centers that marked a change in the balance of power between retailers and suppliers (Fernie and McKinnon, 2003). Unprecedented levels of efficiency began to emerge as retailers massively reduced inventory levels and lead times (Fernie et al., 2000). Further efficiencies and cost reductions occurred when retailers used third-party logistics (3PL) service providers (Smith and Sparks, 2004).

In the late 1980s information began to flow more easily throughout the supply chain due to developments in electronic point-of-sale (EPOS) data and its transmission via electronic data interchange (EDI). In the early 1990s, grocery retailers moved away from product-specific warehousing to multi-temperature composite warehousing and distribution (Smith and Sparks, 2004). Simultaneously, firms further reduced inventory levels in the supply chain using just-in-time approaches; instead of bulk deliveries to regional distribution centers retailers demanded smaller, more frequent deliveries. This step greatly reduced inventory levels held in regional distribution centers but also hurt system-level efficiency (Whiteoak, 2004) and highlighted the increasing impact of logistics on direct product costs as well as the importance of collaboration within the supply chain as a tactic to minimize costs. 
Grocery retailers then began to focus on primary distribution to warehouses or regional distribution centers requiring suppliers to channel orders through primary consolidation centers (PCC) operated by third-party firms (Fernie and McKinnon, 2003). Other initiatives — to the great frustration of hauliers (Hingley et al., 2006) - included a significant increase in backhauling (IGD, 2002), using suppliers' delivery vehicles to support inbound supplies (supplier collection) and to deliver from regional distribution centers to stores on return journeys (onward delivery). Despite some reservations these initiatives improved lead times, delivery frequency, and consignment sizes (Fernie and McKinnon, 2003).

Factory gate pricing (FGP) also improved backhauling and granted grocery retailers greater control of inbound distribution (Potter et al., 2006). This pricing tactic considers contractual arrangements between suppliers and retailers as well as the physical movement of goods. Thus, FGP reflects the ex-works price for a product plus the cost of transport and optimization by the purchaser.

\subsection{Collaboration in UK Grocery Supply Chains}

Logistics relationships in Europe comprise an almost equal split between traditional or transactional and collaborative or partnership relationships (McIlraith, 1998). However, collaboration remains relatively new and within retail supply chains it has been greatly informed by work on collaborative planning, forecasting, and replenishment (CPFR) activities developed in the 1990s (Barratt, 2004).

Studies across several industrial sectors including retail show that collaboration enhances innovation and performance for collaborating firms (Soosay et al., 2008) but demands a collaborative culture (i.e., propensity for collaboration), trust, mutuality, and information exchange as well as senior management support and sufficient resources (Barratt, 2004; Lindgreen et al., 2009). Conversely, managerial inertia and a focus on parochial, short-term results negatively affect performance and customer service and create conflicts in the supply chain (Simatupang and Sridharan, 2002). Further, collaborative frameworks based solely on marginal relationships cannot deliver superior performance (Bailey and Evans, 2006).

Yet collaboration among supply chain partners (Mason et al., 2007) underlies supply chain management $(\mathrm{SCM})$ development where SCM represents an overarching, total systems perspective that includes relationship management across network firms, purchasing, customer service, and cost control with an objective of total supply chain satisfaction (Larson et al., 2007; Lindgreen and Wynstra, 2005). Logistics and physical distribution management (PDM) often appear as subsets of SCM (Stephens, 2006). Collaboration in this context helps 
supply chain partners address inefficiencies such as excessive inventory, duplication of activities or a lack of coordination in their interfirm processes.

However such collaboration is mostly vertical rather than horizontal among suppliers, intermediaries and retailers. For example, Smith and Sparks (2004) highlight how Tesco's Internet-based data exchange system minimizes grocery lead times and Fernie and Hart (2001) describe how legislative pressures regarding packaging encouraged collaboration between grocery suppliers and retailers. Pramatari (2007) and Kaipia and Tanskanen (2003) also note the benefits to grocery retailers of initiatives such as vendor-managed inventory and CPFR. Frankel et al. (2002) even quantify these benefits for Wal-Mart which shaved 11 days off its lead times and improved stock levels and sales. Another popular area for collaborative developments is radio frequency identification (RFID) where RFID tags and transmitters can enhance timely information sharing (Angeles, 2005; Hingley et al., 2007; Pramatari, 2007).

Regarding horizontal collaboration, Christopher (2005) concludes that supply chains rather than firms compete so firms may be reticent to collaborate. However, other authors disagree with this principle. Fernie and McKinnon (2003) claim that increased efficient collaboration between suppliers would encourage greater collaboration among primary distributors while Mason et al. (2007) propose that horizontal collaboration gives firms more flexibility in combining and sharing capabilities, citing examples in the grocery sector of centralization, Internet-based tracking systems, shared pallet networks and regional and central distribution hubs. IGD (2006) has highlighted the common use of standardized replenishment trays and roll cages. Whiteoak (2004) also argues that the profusion of third parties creates at least as many opportunities for collaboration across as along the supply chain, which implies the promise of improved optimization. However, other authors note the precarious nature of multiple grocery retailers' relationships with primary producers (e.g., Aastrup et al., 2007; Grant, 2005; Hingley, 2005; Kumar, 2005; Robson and Rawnsley, 2001).

Despite questions about grocery retailers' enthusiasm for horizontal collaboration Stephens and Wright (2002) found anecdotal support for PDM collaboration among them (e.g. Tesco, Sainsbury's, Asda and Safeway) but a distinct lack of interest in the idea of wider and deeper multiple-retailer collaborations, due to fears of lost competitive advantage. Stephens (2006) addressed these issues in an expansive study of grocery retail centers, retailers, and hauliers and showed that collaboration is possible if external factors such as resource shortages, legislation and social and environmental pressures exert influence. 
However, this pressure must be of such magnitude that retailers cannot control the situation. Stephens concluded that horizontal collaboration is more likely if brokered by a third party.

The limited research available on horizontal collaboration among grocery retailers implies a need for significant external pressures beyond the control of retailers. For example, a third party of sufficient expertise and size might facilitate collaboration and provide protective assurances for the competitive advantages of retailers. Rising commodity and energy costs, combined with increasing environmental legislation, also could force grocery retailers into radical action to manage their costs more efficiently. The increasing complexity and costs of modern supply chains (Christopher, 2005) may make grocery retailers more willing to embrace new alternatives to respond to supply chain pressures.

\subsection{Fourth-Party Logistics (4PL)}

Fourth-party logistics (4PL) relies on an outsourcing provider to neutrally manage the entire logistics process. Unlike 3PL service provision 4PL combines process, technology and management (Mukhopadhyay, 2006). All parties in a 4PL arrangement contribute equity and distribution assets including systems capability, strategy development and process reengineering skills. PDM staff relocate to the new firm which is treated by those involved as a strategic rather than tactical partner and supply chain orchestrator. The focal firm uses its knowledge to manage and integrate the supply chain and turns to specialist providers of logistics services if existing expertise or capacity is not available.

We illustrate a sample 4PL involving two grocery retailers and their third-party arrangements with suppliers and LSPs in Figure 1. The two separate supply chains of the two retailers, supplier facility, PCC, and regional distribution center feed into the joint venture 4PL and receive store deliveries.

\section{\{Take in Figure 1 here\}}

Christopher (2005) submits that such a venture contains four key components:

- Systems architecture and integration skills.

- A supply chain control room.

- The ability to capture and utilize information and knowledge across the network.

- Access to best-of-breed asset providers. 
Existing physical distribution networks operated by individual retailers already incorporate these components which suggest minimal technical barriers. Also, electronic communications systems already link 3PL suppliers and retailers through EDI. The major stumbling block may thus be retailers' willingness to engage in 4PL (cf. Tesco, 2007a, 2007b).

The highly specific nature of assets involved in a joint venture should negate the likelihood of opportunistic behavior (Bourlakis and Bourlakis, 2005). In the automotive industry, Dyer (1997) finds that transaction costs fall when firms with high asset specificity enter partnerships (Cottrill, 2000). Major grocery retailers have honed system innovations by the automotive sector; car manufacturers even use processes perfected by retailers (Truss et al., 2006). However, the automotive industry still leads in 4PL. For example, to reduce supply chain costs General Motors (GM) formed a 4PL joint venture with Menlo Logistics called Vector SCM (Schwartz, 2000; Walsh et al., 2001). Each firm reportedly contributed \$6 billion in start-up equity and all of GM's logistics staff transferred to the new firm. Vector SCM serves as a communications hub that integrates all technology systems used by GM's twelve 3PL providers and provides a single point of contact through EDI. Estimations indicate order cycle times declined as much as $75 \%$ from 60 to 15-20 days and customer lead times fell from 12 to 4-5 days. Vector SCM's revenue is linked directly to such order cycle time reductions.

The Vector SCM venture is a 4PL link between only one firm and its 4PL but the complexity and size of this supply chain is such that it provides a good working model of potential results if grocery retailers were to attempt such a venture. It may not be realistic to expect such spectacular order cycle time reductions; grocery retailers already enjoy short lead times. However, smaller reductions may be possible and other significant savings could be realized through enhanced asset utilization.

Because 4PL service providers produce efficiencies, effectiveness and better economic performance (i.e., profitability) there may be a role for them to lead horizontal collaboration among retailers. The nature of their service provision - including independent and objective execution of logistics and supply chain activities such as storage and distribution - allows them to perform as an "honest broker" in relation to individual customers. Accordingly, 4PL service providers might overcome the barriers to successful collaboration identified above including parochialism, interfirm conflicts and coordinating various competing interests. Such attributes are particularly useful and important in horizontal collaboration where skepticism about such ventures remains high among retailers (Grant et al., 2008). 
Kaufman et al. (2000) present a collaboration typology for strategic suppliers, based on levels of collaboration and technology. We predict that the intensity (or level) of collaboration and the complexity (or level) of collaborative distribution provides an appropriate typology to consider and investigate the usefulness of outsourced logistics in collaborative, particularly horizontal, modes shown in Figure 2.

\section{\{Take in Figure 2 here\}}

For low levels of complexity and collaboration intensity a transactional 3PL relationship may suffice whereas if distribution complexity increases a relational 3PL arrangement may be more appropriate. However if there is high intensity a 4PL arrangement may be appropriate such that the provider operates PDM on an arm's-length basis for the customer whether solving problems in a less collaborative distribution environment or becoming a specialist or consultant.

In summary, vertical collaboration between retailers and suppliers is commonplace in mature grocery supply chain systems but resistance remains to horizontal and network integration that occurs in other sectors. This resistance may reflect a lack of ability, interest or determination or could simply imply that powerful retail manager gatekeepers block its implementation due to their own self-interest. To investigate these issues we propose four key research questions:

RQ1. Do logistics service providers have the ability and willingness to enter into 4PL relationships?

RQ2. Do senior retail managers support 4PL?

RQ3. What safeguards are necessary to facilitate $4 P L$ collaboration?

RQ4. Will 4PL generate sufficient returns?

With RQ1 and RQ2, we attempt to identify reasons for a lack of horizontal engagement. Prior research does not devote sufficient attention to the competitive fears of retailers or whether a firewall separation replicates the costs and negates the benefits of 4PL. Thus, RQ3 aims to identify ways to satisfy such issues. Finally, in accordance with prior literature that identifies cost and efficiency benefits from collaboration RQ4 seeks to identify whether 4PL truly generates sufficient financial or other returns. 


\section{Methodology}

The nature of 4PL is complex (Grant et al., 2008; Mukhopadhyay, 2006) and we needed an approach that could fully study complex processes that have not previously been examined and take into consideration a large number of variables (Matthyssens and Vandenbempt, 2003; Yin, 1994). Thus, we employed qualitative methods to generate rich information (Eisenhardt, 1989; Lindgreen, 2008).

\subsection{Sampling Procedure and Sampled Firms}

The identities of the participating firms are not disclosed for confidentiality reasons. It quickly became apparent that many suppliers were reluctant to voice their opinions fearing a loss of business from retailers. Despite these concerns we were able to develop seven cases which is appropriate to study these highly complex cases and improve certainty (Beverland et al., 2007; Yin, 1994).

We considered all large UK grocery retailers and attempted to contact them in writing and with follow-up efforts though we encountered great reticence to discuss the sensitive issues raised by this study. However, Retailer $X$ agreed to take part as one of the leading UK grocery retailers; it is representative of the handful of chains that dominate the sector. Typical for the sector this retailer's relationships with its suppliers and logistics providers have largely reached a maturity stage. From the immense number of potentially available suppliers (Potter et al., 2006) we selected three: Supplier W, an industrial products supplier, and Suppliers $Y$ and $Z$, broad food products suppliers.

For the logistics service providers, we employed a simple criterion to identify respondents: we considered only those actively engaged in a close relationship with a retailer, which narrowed the field to a few select firms. Three large and significant LSPs eventually agreed to take part. LSP A is an international logistics provider with turnover of nearly $£ 2$ billion. The European market is its core geographical focus and the logistics provider is heavily involved in grocery retail logistics. $L S P B$ is a well-known firm not directly involved in grocery physical distribution management. $L S P C$ is a large global firm responsible for a wide range of supply chain services across diverse industry sectors including grocery. As with the supplier sample the logistics firms agreed to participate only with the agreement that no identifying information would be revealed about them or their business context. 


\subsection{Data Collection}

We collected data through in-depth interviews and secondary data. The interviews at the firms' headquarters averaged three hours each and included full-time employees responsible for supply chain collaboration. Because they were actively involved in supply and logistics decisions they offered the richest source of information about 4PL management.

The interview questions focused on a descriptive history of motivations for 4PL management development, the benefits associated with 4PL management and barriers to its implementation especially for horizontal collaboration. We began interviews with broad, grand tour questions that enabled informants to present the material in their own terms. These questions were interspersed with specific prompts that induced greater insights into specific lines of inquiry. Although we used a short, standardized guide at each site focused on the aforementioned topics our process also reflected emerging topics derived in each interview and the unique aspects of each firm's approach to 4PL management. Each participant received a copy of his or her interview transcript for cross-referencing and to ensure consistency between the recorded data and their intended meaning.

By drawing on secondary data and multiple interviews in each case we developed insights across the firms and achieved a basis for greater transferability of the findings to other contexts (Beverland and Lindgreen, 2010; Eisenhardt, 1989). The secondary data reflected our widespread search of published documents, reports and business press articles. Because the unit of analysis is each firm studied we combined the information from each interview and the secondary sources into a single, case-specific manuscript.

\subsection{Data Analysis}

We analyzed each business to gain an understanding of the processes that the firm underwent to move toward 4PL management. We wanted to explore the benefits of and barriers to implementing 4PL management. Simultaneously we elaborated on theoretical categories through open, axial and selective coding procedures (Strauss and Corbin, 1998).

In open coding, we read and examined discrete parts of the interview transcripts to identify similarities and differences between the firms according to an initial coding scheme. This scheme included topics developed for the four research questions. This classification process resulted in coded passages that the authors discussed to reach a consensus. Axial coding was then applied to reassemble data into categories and subcategories to understand the benefits of and barriers to implementing 4PL management. For example, due to their unique and often particular characteristics different firms tended to focus on specific issues that they believe 
are the most appropriate and relevant in their 4PL management. Beliefs about what constitutes appropriate and relevant issues evolve over time. Finally, we applied selective coding by integrating and refining the theory emerging from our data.

Because each business represents a different degree of 4PL management success, we compared the firms to determine similarities and differences and gain a greater understanding of the associated processes. This cross-firm analysis is essential (Yin, 1994). Finally, to gain a holistic, contextualized comprehension of how firms approach 4PL management we tacked back and forth between prior literature and our data and thereby developed several theoretical categories (Spiggle, 1994).

Throughout, we applied the criteria of credibility, transferability, dependability, confirmability, integrity, fit, understanding, generality and control to improve both the research quality and the trustworthiness of the findings (Beverland et al., 2010). To meet these criteria we conducted multiple interviews, established our own independent interpretations of the findings and allowed respondents to provide feedback on our initial findings. All interviews were conducted by the same interviewer and additional colleagues performed the independent coding of the transcripts, which reduced the potential for bias (Lincoln and Guba, 1985; Strauss and Corbin, 1998). Table 1 provides further information about the trustworthiness dimension (cf. Beverland et al., 2010).

\section{\{Take in Table 1 here\}}

\section{Findings}

\subsection{RQ1}

Suppliers and LSPs indicated divided opinions about LSPs' ability to manage and operate 4PL and willingness to become involved. LSP A was very confident in its ability to manage 4PL and this enthusiasm may have resulted from its ongoing, effective operation of a 4PL on behalf of a major grocery retail supplier by managing the storage and national distribution of a significant range of products throughout the UK and outsourcing capacity as required.

Similarly, LSP C outlined the positive benefits of shared information and best practices, obtained from working with other LSPs in 4PL but indicated that other firms may be wary and protective of their turf fearing the potential loss of business that could result from dealing with competitors. This point was also a general fear among the suppliers for whom collaboration was a barrier because competitive behavior was always a worry. LSP B 
revealed less confidence in the ability of LSPs to manage 4PL operations in grocery logistics but also noted that providing a fully integrated service for the customer was its goal.

Suppliers tended to view the situation from an operational perspective and had a general opinion that major LSPs could manage 4PL. Supplier Y noted that consolidators managing primary collections for supermarkets rely on outsourced help to contend with seasonal peaks, which indicates that 4PL activities are already taking place, and added that current systems could cater to multi-site collections which are a necessity if retailers adopt a 4PL management system.

Supplier Y's claim was thoroughly rebuked by Retailer X; however it did concede some potential for an arrangement to work in non-food lines as competition among retailers is less intense in this area:

There might be an opportunity for us to share a container and get an honest broker 4PL to coordinate a deal with a load of 3PLs with a quantity of [non-food products] and send them over to a country where every retailer takes a portion of the buy (Retailer X).

This arrangement was echoed by Supplier W, which found a duplication in container loads of products coming from Asia to UK manufacturers, suppliers and ultimately retailers. Collaboration would result in more efficient load fill. However, Suppliers Y and Z both offered negative sentiments about an LSP's ability in this case; for example Supplier Z highlighted how its primary distribution deteriorated when it switched from a local haulier to the incumbent primary haulier employed by retailers.

Further, LSP A noted concerns about conflicts of interest if routes were not carefully managed and one retailer were to miss a delivery at the expense of another and that

.... 4PLs would struggle in general freight and movement.

These sentiments were echoed by Retailer X, who was skeptical of LSPs' ability to manage 4PL and scathing in its assessment of some LSPs claiming that only $20 \%$ provided satisfactory service.

Retailer X also questioned the ability of LSPs to communicate effectively with retailers and suppliers. As firms grow in size communication becomes more important as the number of links in the chain increase. If current levels of communication are unsatisfactory it would be impossible for a 4PL to function effectively. There would be no chance for split deliveries or collections adequately timed to facilitate schedules that could satisfy all parties.

Although opinions were divided regarding LSPs' ability to manage 4PL a bigger concern was the willingness of LSPs to get involved. LSP B is bigger than LSP A but it had little 
involvement in direct grocery retail logistics other than replenishment unit management and thus would have been forced to subcontract to rival firms, which was a significant concern:

If a 4PL was run by Wincanton or DHL for example, subcontractors would be wary about getting involved because they will be in a situation where they will be forced into giving their prices to the primary firm. They would also question if they were getting a fair shot at any contract ahead of sister firms of the primary contract holder (LSP B).

Thus, major LSPs appear reluctant to get involved in a relationship with clear potential to undermine their negotiating strength, not only in relation to the 4PL but also for external businesses. From a business perspective it would be preferable to deal directly with retailers, no matter how ruthless or single-minded they are, than to provide tactical information to competing LSPs. If major LSPs were reluctant to enter into partnerships related to the 4PL it would be unlikely to function.

LSP A believed that IT development is a big driver for 4PL. However, the use of bespoke IT systems also entails significant investment as bespoke systems cannot be operated by two firms. LSP B referred to the reluctance of LSPs to make significant financial investments in IT systems but LSP C did not believe 4PL would require much additional IT as most of the infrastructure would be the same as that already in place with a 3PL. Supplier W believed it was a question of which party would make the first move in investing and consequently firms often waited for other channel members to do so. LSP B raised the issue of investment in replenishment units and automated replenishment handling systems. Questions also surrounded whether competing retailers would willingly agree to work with such bespoke systems given the difficulty IGD (2006) identified with standardizing replenishment units alone. The likely reticence of retailers is underscored by Retailer X's admission that bespoke systems are not user friendly.

Prior literature often has identified negative sentiments related to the retailer-supplier dynamic (Grant, 2005; Kumar, 2005; Robson and Rawnsley, 2001). These notions were also reflected in the comments of both suppliers and LSPs who indicated that a 4PL could negatively affect supplier-retailer relationships. The overriding viewpoint of suppliers was that PDM structures created by retailers collaborating in a 4PL would be so overwhelming that their role would be reduced to a commodity status. Supplier W was keen to protect its brand and felt that branding exemplified its unique characteristics which made it less likely to collaborate in logistics when it had direct access to customers through its unique product identity. 
Regarding supply chain power (Grant, 2005; Hingley, 2005; Kumar, 2005) and the effects of an imbalance of power between retailers and suppliers, Supplier Y considered the approach of smaller retailers far more agreeable than that of major retailers and called smaller retailers more partnership-oriented whereas major retailers were dictatorial in their approach to PDM. Supplier Z was concerned that any proposed 4PL would lack the flexibility to react to local circumstances and was fearful of the increased size.

The general consensus of the suppliers was that a major overhaul to extant structures would negatively affect their current dynamic with retailers. Supplier Y believed that changing the PDM model would result in replacing existing transport partners with contractors favored by the 4PL managing firm, altered supplier routes and a loss of preferential timing. These changes might affect service levels which in turn would harm relationships with retailers.

In response to the suggestion that their current supply chain structure could be simplified through 4PL, suppliers expressed reservations and hinted that 4PL might actually add complexity to an already complex situation. Supplier Z contended that a major change in PDM would likely jeopardize local relationships and ultimately service levels. They were also cautious about how cost purges initiated by major retailers would affect not only supplier and retailer relationships but also LSP and retailer relationships; it emphasized its view of the tumultuous state in this market where retailers granted logistics operations to the lowest bidder.

A classical and widely documented view of interfirm relationships refers to the producerretailer relationship, however LSP B noted that in the retailer-supplier-LSP trinity LSPs were also suppliers and this had consequences for rationalization and the balance of power:

I think suppliers and LSPs are not going to have an easy life. The power will remain with the procurement people ... in certain industries there will come a realization among the suppliers that amalgamation of the supplier base is the only way and through this they [buyers/retailers] will gain more power (LSP B).

LSP A agreed that the balance of power, which originally favored major manufacturers, had swung to retailers but it also asserted that manufacturer amalgamation and increased horizontal collaboration among manufacturers was moving the balance of power again. LSP $\mathrm{C}$ found it possible to work with retailers, but believed that retailers had to be open with their communications to enable the 4PL to work. The relational approach adopted by LSPs A and $\mathrm{C}$ to deal with retailers contrasted strongly with that of LSP B which considered such 
exchanges driven by transaction costs. Thus, LSPs A and C appeared ideal candidates to manage a 4PL whereas LSP B was not.

The positive orientation of LSP A and C towards the retailer-LSP relationship was corroborated by Retailer X, which considered the relationship among certain suppliers, LSPs and itself to be of the highest order. The implication is that large suppliers have little to fear from a 4PL because they already provided the volumes and operated at standards that retailers find agreeable. Smaller firms should be more concerned about whether they are prepared to collaborate with similar suppliers to provide the volumes and service that large scale suppliers currently do.

\section{2. $\mathrm{RQ2}$}

Whether or not retailers are willing to participate in horizontal collaboration is the key driver of 4PL. Stephens and Wright (2002) and Stephens (2006) conclude that PDM collaboration among major retailers is likely only when external forces influence the retail sales environment so much that they can no longer counter them with initiatives of their own.

In this vein, Retailer $\mathrm{X}$ noted that green issues were driving consumer choices and the use of environmentally friendly management techniques as marketing tools; this point was echoed by the suppliers and LSPs. Retailer X was concerned with collaborative strategies to combat cost pressures and all three suppliers expressed similar views in relation to responses to the current economic environment. Retailer $\mathrm{X}$ also identified horizontal collaboration examples, though not to the extent that LSP A did:

I am aware that there are certain high streets that are difficult to access and I think that

Marks \& Spencer and Asda, certainly [as] two retailers not with competing activities use one 3PL to deliver stock to the two stores, one on the left hand side of the truck and one on the right hand side (LSP A).

Such levels of collaboration among retailers would have been unheard of in the past and this may be as close as retailers are willing to get (Grant et al., 2008). From an operational perspective there may be little to gain. LSP B explained that it would be disappointed not to achieve at least $90 \%$ capacity utilization on its main trucking routes but it considered $75 \%$ efficiency on primary collection routes were high. LSP C stressed the importance of better fleet utilization as a benefit of 4PL and, as a result, better space management and warehouse efficiency gains.

Retailer X's serious reservations about 4PL could be interpreted as a lack of willingness with operational considerations at the heart of the matter. Its replenishment was based on 
real-time data and they explained that a second retailer involved would need data access from its competitor to ensure the maintenance of warehouse stock at optimum levels. Such access would provide both retailers complete visibility in terms of sales trends but overcoming this unwelcome visibility issue would require a second, parallel system that would immediately double the overhead and add significantly to system complexity. These increases did not create a compelling argument on behalf of 4PL for Retailer X.

Such operational issues can always be resolved but far greater obstacles remain. Sangam (2007) shows that the use of 3PL increases retailer focus on its core competencies, e.g. store operations and that any proposed 4PL would magnify this focus. Therefore, retailers would likely leave supply chain activities to contract service firms, yet the LSPs in this study contended that control of the supply chain meant far more to retailers than just asset utilization or reduced environmental impact.

Retailer X reiterated the notion that value in the supply chain involved more than cost and was unambiguous in its view of its position in the retail sector and the impact of that position on any possible retailer collaboration:

Retailers on their own, stand alone I think..... as we have a massive economy of scale and we have an established distribution network which is really excellent, which incorporates bespoke systems and support mechanisms in the supply chain arena. On that basis you would have to say that we are the best. I also think from a cultural point of view it would be very difficult for us to get into partnership with another retailer (Retailer X)

This statement summarized their overall view and negative sentiment toward 4PL. Even if retailers' misgivings could be overcome the potential for financial penalties incurred by poor service levels, resulting from the loss of supply chain control, would become an issue.

If most retailers believe, like Retailer X, that their supply chain structures are far superior to any other collaboration would virtually be impossible because there would be no middle ground for compromise. Retailers also would not allow their supply chains to be managed by external management which would imply their existing retailer supply chain structure was inferior.

Retailer X's belief that control of its own supply chain added to its competitive edge confirmed Christopher's (2005) argument that supply chains, not firms, compete and the strong competition among major retailers appears to depend on their supply chains and their complete control over them.

Among the factors likely to discourage UK retailers from collaborating is the issue of anticompetitiveness. Major retailers have been subject to thorough investigations by the 
Competition Commission (2000) and it is highly unlikely that any retailer would willingly enter into an arrangement that might incur the wrath of the investigative authorities.

An overwhelmingly negative perspective regarding retailers' willingness to be involved in 4PL spans all participants in this study. Many of the operational issues could be resolved and the lukewarm enthusiasm of LSPs and suppliers could be surmounted with sufficient financial incentives. But the motivation of retailers to engage in the process is fundamental and it is very difficult to draw any positive findings from this study regarding 4PL as a viable option. Even the weak economic climate does not appear to threaten the hegemony of the major retailers; unless they have a significant change of heart significant horizontal collaboration among major retailers is highly unlikely.

\subsection{RQ3}

The question of requisite safeguards prompted suppliers' negative assessments of 4PL. System transparency was an area of particular concern, apparently as a reflection of the suppliers' beliefs about how 4PL would negatively affect the supplier-retailer dynamic. Supplier W desires trust in supply chain relationships but fears that sharing knowledge may result in its exploitation. Lack of trust caused Supplier $\mathrm{Y}$ to note concerns about the possibility of 4PL being used as a tool by LSPs and retailers to generate extra profit at the expense of the suppliers.

In contrast, LSP C believes that communication and the exchange of ideas and information needs to be open; because it and other LSPs operate in an open book accounting environment anyway, it has nothing to lose.

However, there was conflict between the suppliers and LSPs regarding the ultimate destination of any savings generated through 4PL activities. Supplier Y was not convinced savings would be fairly distributed. Supplier Z was concerned about transparency from the perspective of product management, explaining that products disappeared from view once they entered the supply chain and could be lost in the system. In such instances neither the LSP nor the retailer would take responsibility for the loss, forcing the supplier to provide replacement products.

Supplier Z asserted that RFID would be an essential safeguard for any 4PL, supporting Pramatari's (2007) claim that RFID can increase system transparency. Although RFID would improve traceability of products in the supply chain, retailers also would be obligated to share product movement visibility with all parties. 
The cost of RFID and who pays for it are also key issues. Supplier Y was very cost conscious in relation to transport and if it had to pay the costs associated with RFID tags and standardized replenishment units it could not obtain any of the cost savings generated by improved capacity utilization.

In their analysis of 4PL food chains Bourlakis and Bourlakis (2005) suggest that the highly specialized nature of the assets involved in the distribution collaboration negates opportunistic behavior. However, the potential for opportunistic behavior within the 4PL was an issue for Retailer X and LSP B, even though such behavior seemingly should be a greater concern among more subordinate firms..

As such LSP B believed power is always with the procuring party in the relationship. The financial power of some parties in a 4PL arrangement would be of such magnitude that punitive action levied against those that failed to comply with contractual obligations would be relatively insignificant, rendering disciplinary action ineffectual.

Rather than transparency, all participants in this study agreed on the need for information security as well as for dedicated systems within the 4PL to ensure the protection of sensitive information. LSP A believed such fears could be allayed though because existing processes and procedures would be sufficient to protect sensitive information and the interests of each party.

\subsection{RQ4}

Suppliers and LSPs both saw potential costs benefits with 4PL, in fleet utilization and corresponding warehouse operational efficiencies.

Supplier Y identified 20-30\% slack in the PDM system largely as a result of insufficient attention to backhauling. It believed that the key reason for the underutilization of backhauling was that it became cost effective only at high volumes. However, a proposed 4PL would create large product volumes. Moreover, cooperation between two major retailers would increase the number of drop points and reduce the likelihood of vehicles moving in any direction without heading toward or passing a potential drop point. Supplier Z also referred to inefficiencies in backhauling explaining that trucks always arrived at the site empty, and yet some retailers employed a second distributor to deliver replenishment units. Thus, they underlined how a centrally managed distribution system would enhance the possibility that one distributor could manage full and empty replenishment units in combination. 
Suppliers and Retailer $\mathrm{X}$ believed that if such a joint venture could be presented appropriately, it would also offer a particularly effective public relations tool in relation to reduced environmental impact. Further, Retailer X emphasized that this issue and the rising cost of commodities were influencing their distribution management.

Supplier Y worried that increases in volumes required increased backhaul utilization and would necessitate considerable local consolidation. It explained that it had explored local consolidation as a means to achieve better distribution cost management but found that it was not cost effective. Again, its experience confirmed that volumes are critical and that consolidation of niche products has been far less cost effective than direct collection of specific niche product lines. These experiences contrasted with arguments by Fernie and McKinnon (2003), Mason et al. (2007), and Whiteoak (2004), who extol the virtues of increased horizontal collaboration. However, if 4PL jeopardizes niche products because they cannot be distributed in a cost-effective manner retailers will drop them from stock and reduce consumer choice.

The LSPs and Retailer X emphasized the need for suppliers to buy into the 4PL idea because greater centralization of PDM would demand greater quantities of stock held at PCCs. The current retail model uses PCCs for central stockholding only but they would form a more integral part of 4PL by providing the opportunity for backhauling on trucking routes. Thus a significant hurdle to 4PL development arose: retailers and LSPs would gain much greater asset utilization at the expense of the supplier.

If significant increases of stock were required and associated costs increased the costs ultimately would be transferred to the consumer through increases in the price of the product and totally negating any benefit the consumer may have been expecting. Further negative impacts could result if service levels slipped and affected sales volumes. Suppliers would likely counteract this eventuality with higher product prices.

Many authors have noted the importance of service levels in relation to PDM (e.g. Prahinski and Kocabasoglu, 2006) and all suppliers in this study also mentioned it. The flexibility of current systems enables suppliers to maintain excellent service records with retailers. Suppliers were conscious that centralizing logistics management could negatively influence their current service levels if they lost the ability to manage and react to situations locally. Consumers would likely find a substitute product if their first choice was not available, so even if the reduction in the service level did not affect retailers it would affect individual suppliers. From this perspective, the suppliers worried that a cost-saving initiative such as 4PL may benefit retailers only. 


\section{Conclusions}

This study identifies a consensus of opinion from the participants that the time is right for changes in current PDM structures associated with grocery and wider retail supply chains in the UK. The participants agreed certain elements would enhance the current situation such as the potential for increased asset utilization and the marketability of a more environmentally sound approach to distribution management. Other less tangible benefits included the reputation benefits of being associated with such innovations. These findings appear in-line with literature that has promoted the benefits of innovation and horizontal collaboration in retail supply chains (Bailey and Evans; 2006; Barratt, 2004; Simatupang and Sridharan, 2002).

However, only suppliers and LSPs showed the necessary willingness to participate in 4PL innovations including horizontal collaboration for increased efficiencies and customer service and reduced costs. We found a distinct lack of retailer willingness to sustain a 4PL operation and horizontal collaboration. This reticence likely relates to the power or control issues identified by Grant (2005), Hingley (2005), Kumar (2005) and Spekman et al. (1998) and their effect on the retailer-supplier dynamic continues to be detrimental. However, retailers have reached their current positions through significant horizontal mergers and acquisitions rather than more friendly collaboration and may have arrived at a point of horizontal saturation, especially with regard to competition law.

Thus, PDM means far more to retailers than cost efficiency, as verified by the LSPs. Retailers place such a value on service levels and protecting sensitive sales information that it is difficult to envisage any situation where they would collaborate so much that they shared PDM.

As such, retailers as gatekeepers and channel leaders are motivated more by safeguards against competition than by collaborative savings. We believe the adapted typology in Figure 2 offers a useful operational process for 4PL, but the lack of retailer support was disappointing which prompted us to develop a future structure for PDM systems using 3PL and 4PL in retail as shown in Figure 3. A 4PL would still provide benefits for suppliers but either it or traditional 3PL providers would need to offer the usual direct and unique deliveries to retailers — with all the attendant inefficiencies in operations, costs and the environment associated with in this final link in the grocery supply chain

\section{\{Take in Figure 3 here $\}$}


The issue of horizontal collaboration in grocery and other retail supply chains has not been sufficiently addressed in prior research. Previous studies have focused on potential efficiency gains from 4PL service provision but have not seriously considered a retailer's competitive power play. It is hard to see how sufficient returns might be realized with retailers' emphasis on supply chain secrecy. We expected much more openness and enthusiasm for 4PL and horizontal collaboration; in this sense our findings are a little disappointing. Nevertheless, this study confirms a serious issue: how can retailers get comfortable with the essence of 4PL so that they can achieve any available benefits?

Regarding our proposed typology, the two dimensions of collaboration intensity and complexity of collaborative distribution are supported by our study participants. The more intense and complex the distribution and collaboration operations become, the more the 4PL must specialize in terms of assets and technology, particularly information flow assisted by techniques such as RFID. If they do not, the benefits of superior performance will not be achieved, as noted by Bailey and Evans (2006).

\subsection{Managerial implications}

This study has identified the scope for greater horizontal collaboration although it may occur at the supplier rather than the retailer level. This potential has been tentatively investigated by one of the suppliers in our study but the issue demands a more vigorous exploration in that this avenue offers the potential advantage of increasing distribution asset utilization without endangering retailer integrity and service levels, as horizontal collaboration between retailers would.

The LSPs highlighted significant PDM horizontal collaborations between major manufacturers, which indicate that such firms have very quickly come to appreciate the cost savings and other benefits gained from collaboration. Those involved in the grocery supply chain should not expect retailers to provide all of the cost management initiative because their primary concern appears to be their own welfare. As the economic environment tightens consumers will expect more from retailers in terms of competitive pricing and this pressure will be passed on to suppliers. To remain competitive, suppliers should turn to greater horizontal collaboration which also represents an opportunity for smaller producers to improve their cost efficiency.

The current economic environment means that all actors in the food supply chain experience increasing pressure to manage costs more efficiently. The attitudes summarized 
herein suggest that external pressure is not yet sufficient to encourage close retailer collaboration. Its effects should not be completely discounted though because external pressure may still offers a means to manage costs effectively.

\subsection{Limitations and further research}

Several limitations related to this study would benefit from further research. First, we find no clear consensus from LSPs and suppliers about existing levels of horizontal collaboration between retailers outside the grocery sector; some of the participants are engaged in other sectors. Further study would facilitate a clearer identification of current activities and areas for improvement.

Second, a specific cost analysis of the impact of 4PL involving major grocery retailers may highlight sufficient returns that would compensate for the loss of value in the complete supply chain control.

Third, a 4PL operation may be feasible among retailers that own significantly smaller proportions of the grocery market rather than those with large stakes. A similar study with smaller participants may yield vastly different and more favorable attitudes, in which supply chain power may be more equitable. These retailers likely have less PDM expertise and fewer resources available for PDM and thus have more to gain from collaboration.

\section{References}

Aastrup, J., Grant, D.B., and Bjerre, M. (2007), 'Value creation and category management through retailer-supplier relationships', International Review of Retail, Distribution and Consumer Research, 17 (5), 523-541.

Angeles, R. (2005), 'RFID technologies: Supply-chain applications and implementation issues', Information Systems Management, 22 (1), 51-66.

Bailey, K. and Evans, B. (2006), 'Understanding the nature of collaboration within fresh produce value chains', Working Paper L06/001, Cardiff Business School, Cardiff.

Barratt, M. (2004), 'Research note: Understanding the meaning of collaboration in the supply chain', Supply Chain Management: An International Journal, 9 (1), 30-42.

Beverland, M.B. and Lindgreen, A. (2010), 'What makes a good case study? A positivist review of qualitative case research published in Industrial Marketing Management, 19712006', Industrial Marketing Management, 39 (1), 56-63. 
Beverland, M.B., Kates, S.M., Lindgreen, A., and Chung, E. (2010), 'Exploring consumer conflict management in service encounters', Journal of the Academy of Marketing Science, 38 (5), 617-633.

Beverland, M.B., Napoli, J., and Lindgreen, A. (2007), 'Industrial global brand leadership: a capabilities view', Industrial Marketing Management, 36 (8), 1082-1093.

Bourlakis, C. and Bourlakis, M. (2005), 'Information technology safeguard, logistics asset specificity and fourth party logistics network creation in the food retail chain', Journal of Business and Industrial Marketing, 20 (2), 88-98.

Christopher, M. (2005), Logistics and Supply Chain Management: Creating Value-adding Networks, 3rd ed., Pearson Education, Harlow.

Competition Commission (2000), Supermarkets: A Report on the Supply of Groceries from Multiple Stores in the UK. The Stationary Office, London.

Cottrill, K. (2000), 'Sharing the risks, riches', Traffic World, 264 (12/13), 10-11.

Day, G. (2000), 'Managing marketing relationships', Journal of the Academy of Marketing Science, 28 (1), 24-30.

Dyer, H.D. (1997), Effective interfirm collaboration: how firms minimize transaction costs and maximize transaction value', Strategic Management Journal, 18 (7), 535-556.

Eisenhardt, K.M. (1989), 'Building theories from case study research', Academy of Management Review, 14 (4), 532-550.

Fernie, J. and Hart, C. (2001), 'UK packaging waste legislation: implications for food retailers', British Food Journal, 103 (3), 187-197.

Fearne, A. and Hughes, D. (1999), 'Insight from industry: success factors in the fresh produce supply chain: Insights from the UK', Supply Chain Management: An International Journal, 4 (3), 120-128.

Fernie, J. and McKinnon, A.C. (2003), 'The grocery supply chain: improving efficiency in the logistics network', International Review of Retail, Distribution and Consumer Research, 13 (2), 161-174.

Fernie, J., Pfab, F., and Marchant, C. (2000), 'Retail grocery logistics in the UK', International Journal of Logistics Management, 11 (2), 83-90.

Frankel, R., Goldsby, T.J., and Whipple J.M. (2002), 'Grocery industry collaboration in the wake of ECR', International Journal of Logistics Management, 13 (1), 57-72.

Garbarino, E. and Johnson, M.S. (1999), 'The different roles of satisfaction, trust, and commitment in customer relationships', Journal of Marketing, 63 (2), 70-87. 
Grant, D.B. (2005), 'The transaction - relationship dichotomy in logistics and supply chain management', Supply Chain Forum: An International Journal, 6 (2), 38-48.

Grant, D.B., Fernie, J., Trautrims, A., and El-Adas, R. (2008), 'Improving service and sustainability in retail supply chains,' Proceedings of the $13^{\text {th }}$ International Symposium on Logistics (ISL) 2008, Bangkok, July, 257-264.

Hingley, M. (2005), 'Response to comments on "Power to all our friends? Living with imbalance in supplier-retailer relationships"', Industrial Marketing Management, 34, 870875.

Hingley, M., Lindgreen, A., and Casswell, B. (2006), 'Supplier-retailer relationships in the UK fresh produce supply chain', Journal of International Food and Agribusiness Marketing, 18 (1/2), 49-86.

Hingley, M., Taylor, S., and Ellis, C. (2007), 'Radio frequency identification tagging: Supplier attitudes to implementation in the grocery retail sector', International Journal of Retail \& Distribution Management, 35 (10), 803-820.

IGD (2002), Backhauling and Factory Gate Pricing. Institute of Grocery Distribution, Letchmore Heath.

IGD (2006), Retail Logistics. Institute of Grocery Distribution, Letchmore Heath.

Kaipia, R. and Tanskanen, K. (2003), 'Vendor managed category management: An outsourcing solution in retailing', Journal of Purchasing and Supply Management, 9, 165175.

Kaufman, A., Wood, C.H., and Theyel, G. (2000), 'Collaboration and technology linkages: a strategic supplier typology', Strategic Management Journal, 21, 649-663.

Kumar, N. (2005), 'The power of power supplier-retailer relationships', Industrial Marketing Management, 34 (7), 863-866.

Larson, P.D., Poist, R.F., and Halldórsson. A. (2007), 'Perspectives on logistics vs. SCM: a survey of SCM professionals', Journal of Business Logistics, 28 (1), 1-24.

Lincoln, Y.S. and Guba, E. (1985), Naturalistic Inquiry, Sage Publications, Beverly Hills, CA.

Lindgreen, A. (2003), 'Trust as a valuable strategic variable in relationship marketing: different types of trust and their implementation', British Food Journal, 105 (6), 310-328.

Lindgreen, A. (2008), Managing Market Relationships, Gower Publishing, Farnham.

Lindgreen, A., Balazs, R., and Glynn, M. (2009), 'Purchasing orientation', Journal of Business and Industrial Marketing, 24 (3/4), 148-153. 
Lindgreen, A. Palmer, R., Wetzels, M.G.M., and Antioco, M.D.J. (2009), 'Do different marketing practices require different leadership styles? An exploratory study', Journal of Business and Industrial Marketing, 24 (1/2), 14-26.

Lindgreen, A. and Wynstra, F. (2005), 'Value in business markets: what do we know? Where are we going?' Industrial Marketing Management, 34 (7), 732-748.

McIlraith, G. (1998), 'Routes to best practice', Logistics Europe, 6 (2), 36-41.

McKinnon, A. and Edwards, J. (2010), 'Opportunities for improving vehicle utilization', in A. McKinnon, S. Cullinane, M. Browne, and A, Whiteing (eds.) Green Logistics: Improving the Environmental Sustainability of Logistics, Kogan Page, London, 195-213.

Macneil, I. (1980), The New Social Contract: An Inquiry Into Modern Contractual Relations, Yale University Press, New Haven, CT.

Mason, R., Lalwani, C., and Boughton, R. (2007), 'Combining vertical and horizontal collaboration for transport optimization', Supply Chain Management: An International Journal, 12 (3), 187-199.

Matthyssens, P. and Vandenbempt, K. (2003), 'Cognition-in-context: reorienting research in business market strategy', Journal of Business \& Industrial Marketing, 18 (6-7), 595-606.

Morgan, R.M. and Hunt, S.D. (1994), 'The commitment-trust theory of relationship marketing', Journal of Marketing, 58 (3), 20-38.

Mukhopadhyay, S.K. (2006), 'The role of 4PL as the reverse logistics integrator: optimal pricing and return policies', International Journal of Physical Distribution \& Logistics Management, 36 (9), 716-729.

Potter, A., Mason, R., and Lalwani, C. (2006), 'Analysis of factory gate pricing in the UK grocery supply chain', International Journal of Retail \& Distribution Management, 35 (10), 821-834.

Prahinski, C. and Kocabasoglu, C. (2006), 'Empirical opportunities in reverse supply chains', International Journal of Management Science, 34, 519-532.

Prakash, A. and Deshmukh, S.G. (2010), 'Horizontal collaboration in flexible supply chains: a simulation study', Journal of Studies on Manufacturing, 1 (1), 54-58.

Pramatari, K. (2007), 'Collaborative supply chain practices and evolving technological approaches', Supply Chain Management: An International Journal, 12 (3), 210-220.

Robson, I. and Rawnsley, R. (2001), 'Co-operation or coercion? Supplier networks and relationships in the UK food industry', Supply Chain Management: An International Journal, 6 (1), 39-47. 
Sangam, V.K. (2007), Global logistics outsourcing trends: Challenges in managing 3PL relationships, [Online] available from http://www.pmac.ca/pdf.practitioner_papers/global_logistics_outsourcing.pdf, [Accessed 22 April 2009].

Schwartz, E. (2000), 'GM eyes cost-savings by outsourcing logistics', InfoWorld, December 18,5 .

Simatupang, T.M. and Sridharan, R. (2002), 'The collaborative supply chain', International Journal of Logistics Management, 13 (1), 15-30.

Smith, D. and Sparks L. (2004), 'Logistics in Tesco: Past, present and future', In Fernie, J. and Sparks, L. (Eds.), Logistics and Retail Management, 2nd ed., Kogan Page, London.

Soosay, C.A., Hyland, P.W. and Ferrer, M. (2008), 'Supply chain collaboration: capabilities for continuous improvement', Supply Chain Management: An International Journal, 13 (2), 160-169.

Spekman, R.E., Kamauff, J.W., and Myhr, N. (1998), 'An empirical investigation into supply chain management: A perspective on partnerships', International Journal of Physical Distribution \& Logistics Management, 28 (8), 630-650.

Spiggle, S. (1994), 'Analysis and interpretation of qualitative data in consumer research', Journal of Consumer Research, 21 (3), 491-503.

Stephens, C. (2006), 'Enablers and inhibitors to horizontal collaboration between competitors: An investigation in UK retail supply chains', Unpublished Ph.D. thesis. Cranfield University.

Stephens, C. and Wright, D. (2002), 'The contribution of physical distribution management to the competitive supply chain strategies of major UK food retailers', International Journal of Logistics: Research and Applications, 5 (1), 92-108.

Strauss, A. and Corbin, J. (1998), Basics of qualitative research, 2nd ed. Sage Publications, Newbury Park, CA.

Tesco (2007a), Our core purpose, [Online] available from: http://www.tescocorporate.com.page.aspx?pointerid=B2F9CD9F4987417B817DF701C0F 2A745 [Accessed 18 November 2008].

Tesco (2007b), Corporate responsibility review 2007, [Online] available from: http://www.tesco.com/corporate, [Accessed 16 December 2008].

Truss, L.T., Wu, P., Saroop, A., and Sehgal, S.T. (2006), 'Enterprise demand sensing in the automotive industry', Journal of Business Forecasting, 25 (3), 22-30. 
Walsh, E., Bradley, P., Gooley, T., and Cooke, J.A. (2001), 'GM shifts global logistics strategy', Logistics Management and Distribution Report, 40 (1), 19.

Whiteoak, P. (2004), 'Rethinking efficient replenishment in the grocery sector', in Fernie, J. and Sparks, L. (Eds.), Logistics and Retail Management, 2nd ed., Kogan Page, London, 138-163.

Yin, R.K. (1994), Case Study Research: Design and Methods, 2nd ed., Sage Publications, Thousand Oaks, CA. 


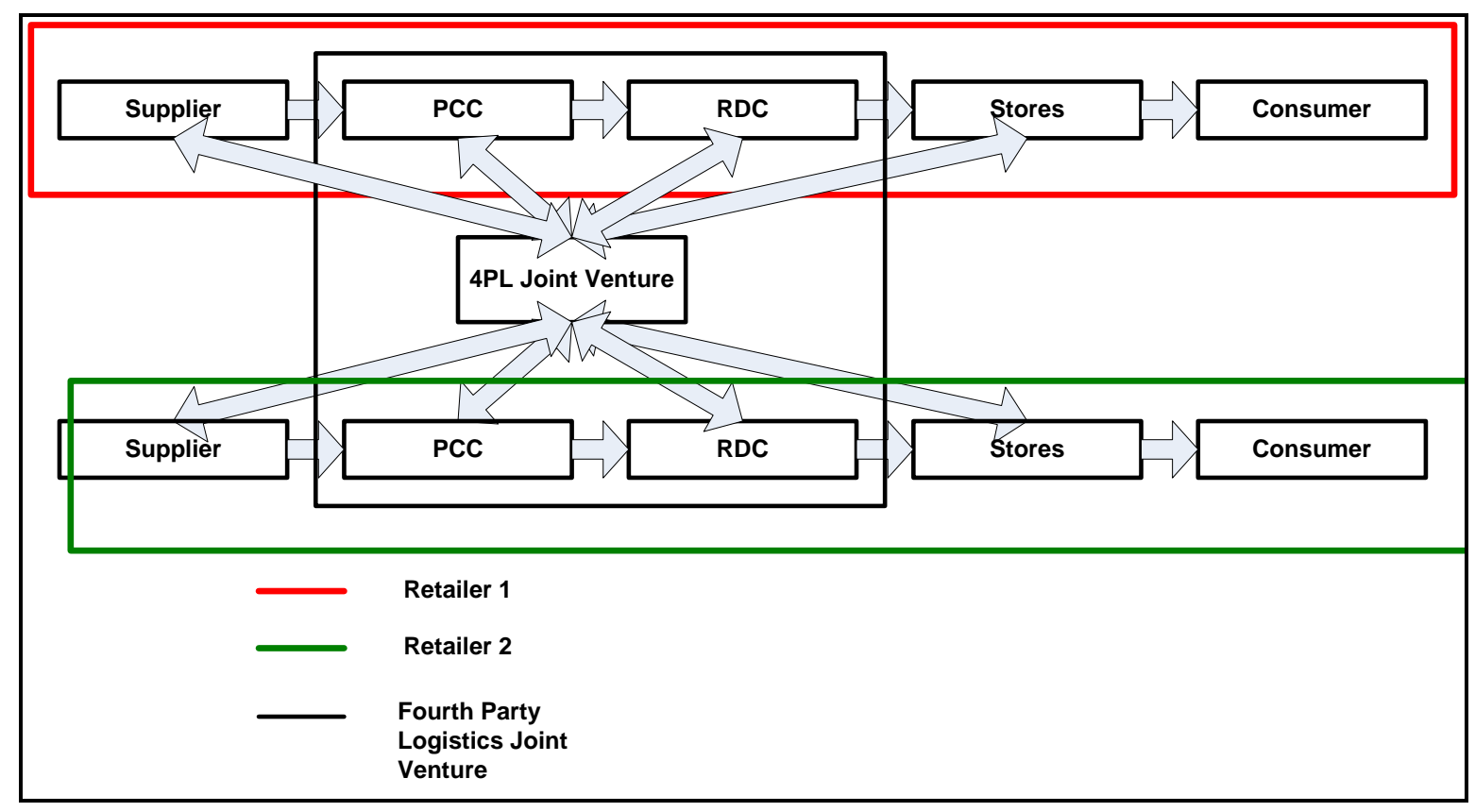

Figure 1: Structure of a fourth-party logistics joint venture 


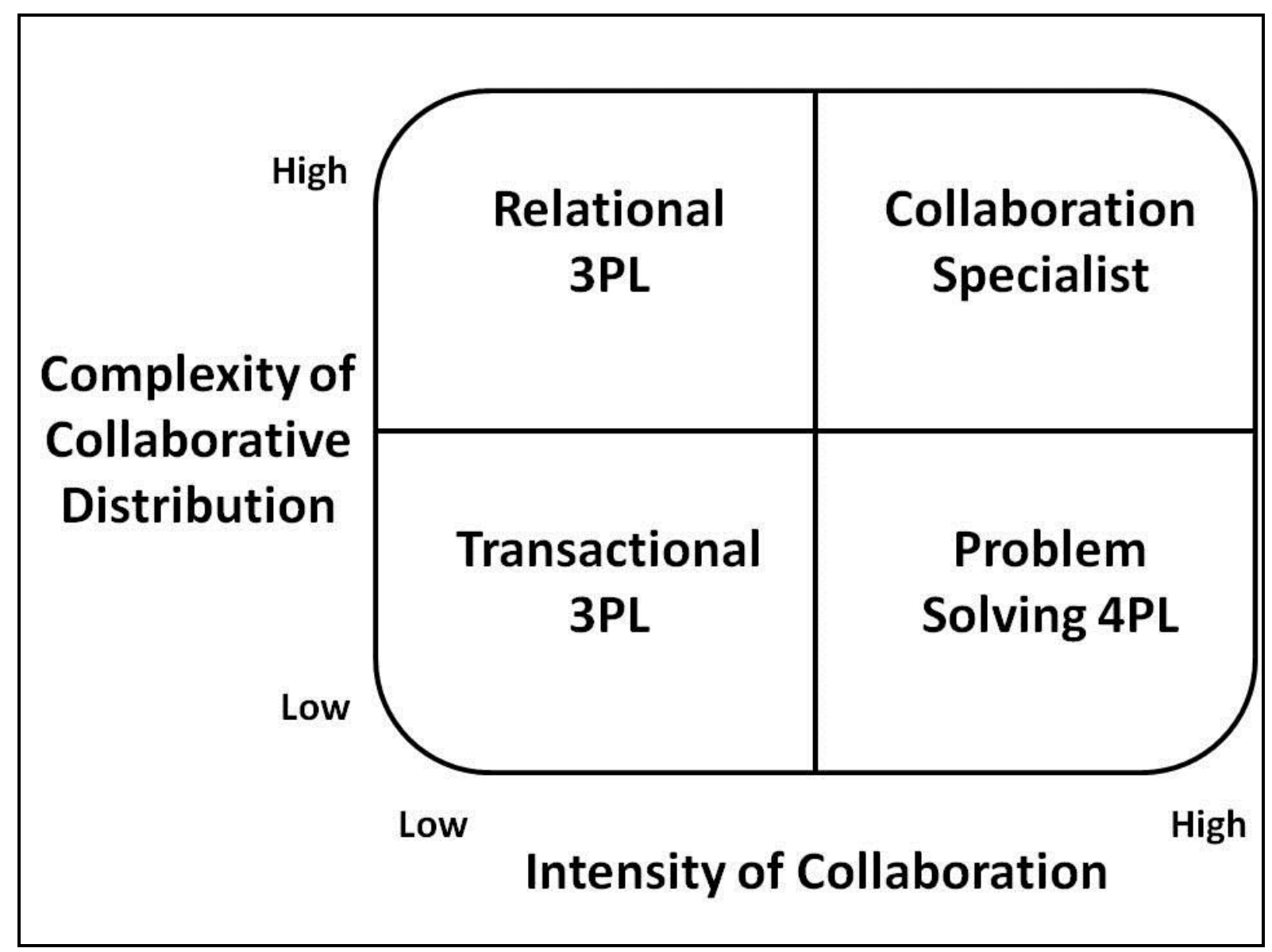

Figure 2: Proposed typology for fourth-party logistics collaboration 


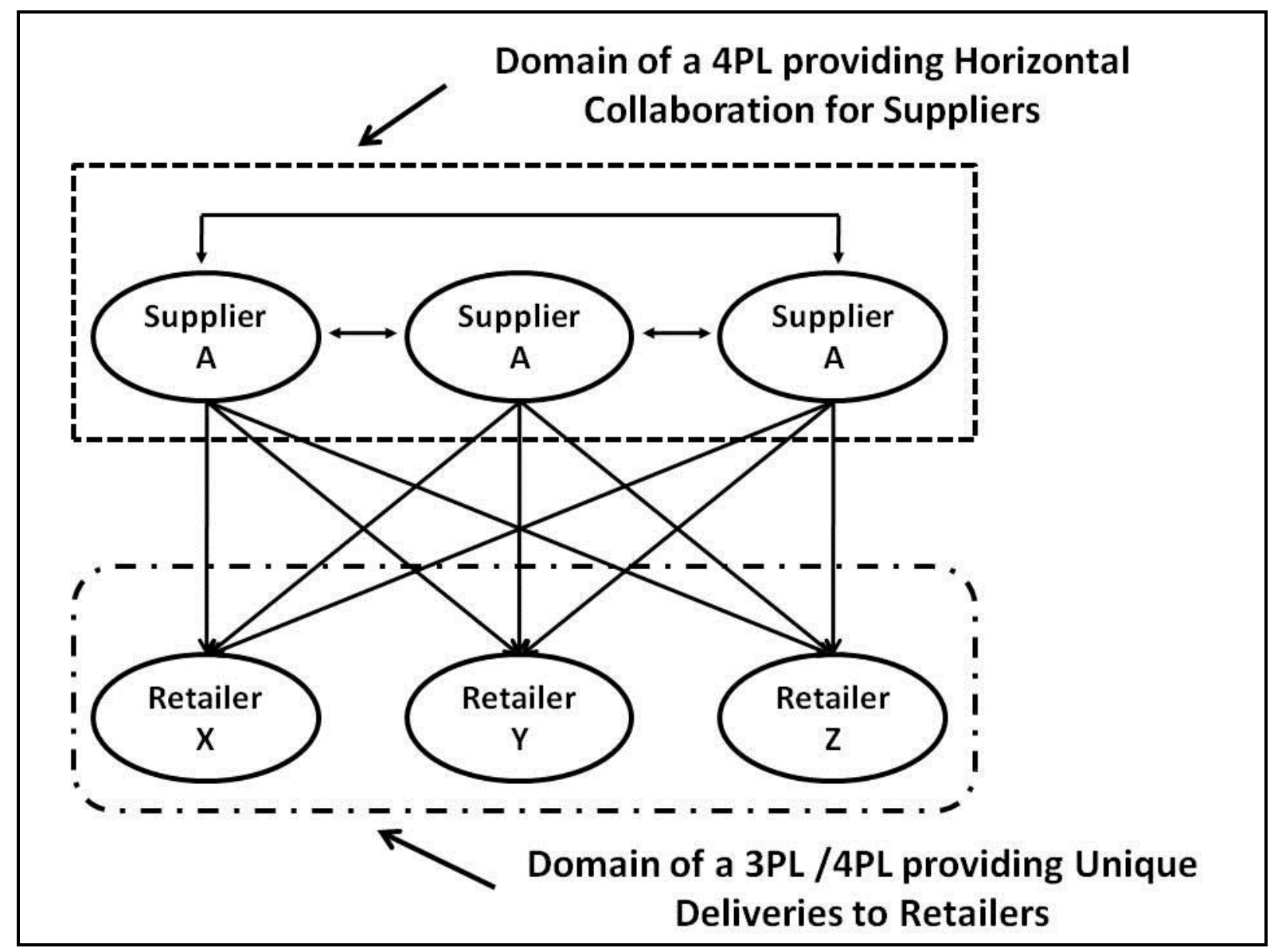

Figure 3: Future structure of 4PL involvement in horizontal collaboration? 


\section{Trustworthiness criterion, and how we address it}

Confirmability $\rightarrow$ Interviews feature knowledgeable informants from case retailers and their suppliers and logistics providers. We conducted discussions with academic colleagues and presented the research findings at our academic institutions. Four researchers analyzed the collected data. Finally, we tacked between literature and data. These efforts help expand and refine our interpretation of the findings.

Credibility $\rightarrow$ Four researchers are involved in setting up the research and interpreting the findings. All informants are invited to provide feedback after the analysis.

Dependability $\rightarrow$ The historical development of 4PL management is discussed; the retailers have largely developed and implemented their 4PL management programs. Because of differences in each retailer's context, we can offer a broader perspective on 4PL management.

Fit $\rightarrow$ The question of whether our findings are in line with what we examine is addressed through credibility, dependability, and confirmability variables (Beverland et al., 2010).

Generality $\rightarrow$ The number and length of interviews enable us to discover multiple aspects of 4PL management development and processes, in particular benefits of and barriers to 4PL management.

Integrity $\rightarrow$ Our interview questions are non-threatening in nature and allow informants to present the material in their own terms. Thus informants are open about the research issues.

Transferability $\rightarrow$ We provide background information on the retailers. We give detailed descriptions of each retailer's development of 4PL management. Finally, we employ a standardized interview protocol, clear procedures for data analysis, and a database that is the input for our qualitative analysis.

Understanding $\rightarrow$ Informants are invited to provide feedback on our initial interpretation. We also present our initial findings at our home institutions, thereby inviting colleagues to question our findings. 